\title{
Cost of Hospitalization for the Patients in Corporate Hospitals in India: A Retrospective Analysis of Five Years of Data from 2012 to 2017
}

\author{
Dinesh Bammidi
}

\begin{abstract}
This is a research article for the 'cost of hospitalization' for the in-patients in private hospitals in India. I restricted the review to the corporate hospitals and analyzed the cost of hospitalization for the patients throughout five years. The average "cost of hospitalization' for in-patients over the years in these hospitals, shows surprisingly less increase and the inflation-adjusted rise of these costs is marginal. This is counter intuitive, and I am publishing this analysis so that there can be further studies dissecting these costs and if this data reflects the accurate picture. If so, it would be interesting to understand why this is so.
\end{abstract}

Keywords: Healthcare spending, Hospital costs, Trend analysis

How to cite this article: Bammidi D. Cost of Hospitalization for the Patients in Corporate Hospitals in India: A Retrospective Analysis of Five Years of Data from 2012 to 2017. Int J Res Foundation Hosp Healthc Adm 2018;6(2):80-81.

Source of support: Nil

Conflict of interest: None

\section{AIM}

To calculate the average 'cost of hospitalization' for the in-patients in corporate hospitals.

\section{OBJECTIVES}

- To derive the cost of hospitalization from the validated and available data.

- To compare the costs over the years.

\section{SCOPE}

Two of the largest corporate hospitals in India by bed strength and by the number of inpatients treated.

\section{METHODOLOGY}

For five years of period of study from (2011-2012) to (2016-2017), the validated data regarding the average

Regional Manager and Consultant

Apollo Speciality Hospitals, Bengaluru, Karnataka, India

Corresponding Author: Dinesh Bammidi, Regional Manager and Consultant, Apollo Speciality Hospitals, Bengaluru, Karnataka, India, e-mail: dinesh.bammidi@gmail.com length of stay (ALOS) and average revenue per occupied bed (ARPOB) were taken from the Annual reports of 'Fortis Healthcare limited' and 'Apollo Hospitals Enterprise limited' respectively, the two hospitals which were considered for this analysis. These numbers were in the published audited reports of these publicly listed companies, and no separate validation was done by me.

Average revenue per occupied bed (ARPOB)/day was calculated based on the available ARPOB/year and (ALOS)*(ARPOB/day) gave me the average cost of hospitalization per patient in that year.

Average revenue earned by the hospitals per patient $=(\mathrm{ALOS})^{*}(\mathrm{ARPOB} /$ day $)$

The same would be the average cost of hospitalization for a patient in that particular year for the particular group of hospitals.

The average cost of hospitalization for the mentioned years was calculated as stated above and the final values are analyzed for year on year and 5-year changes.

\section{Sources of Data}

Annual reports of Apollo Hospitals Enterprise Limited from the years 2012 to 2017

Annual reports of Fortis Healthcare limited from the years 2012 to 2017

\section{ANALYSIS AND RESULTS}

\section{Cost of Hospitalization for Apollo Hospitals Enterprise Limited}

\begin{tabular}{lllllll}
\hline & $2011-12$ & $2012-13$ & $2013-14$ & $2014-15$ & $2015-16$ & $2016-17$ \\
\hline ALOS $^{1}$ & 4.78 & 4.65 & 4.54 & 4.43 & 4.17 & 4.04 \\
ARPOB $^{1}$ & 7466075 & 7929260 & 8644660 & 9264065 & 10901455 & 11508085 \\
$\begin{array}{l}\text { ARPOB/ } \\
\text { day }\end{array}$ & 20455 & 21724 & 23684 & 25381 & 29867 & 31529 \\
$\begin{array}{l}\text { Average } \\
\text { cost of } \\
\text { hospita- }\end{array}$ & 97774.9 & 101016.6 & 107525.4 & 112437.8 & 124545.4 & 127377.2 \\
$\begin{array}{l}\text { lization per } \\
\text { in-patient }\end{array}$ & & & & & & \\
$\begin{array}{l}\text { Yoy } \\
\text { increase in } \\
\text { costs }\end{array}$ & NA & 0.033155 & 0.064433 & 0.045687 & 0.107682 & 0.022737 \\
\hline
\end{tabular}

Cont... 
Cont..

\begin{tabular}{lllllll}
\hline & $2011-12$ & $2012-13$ & $2013-14$ & $2014-15$ & $2015-16$ & $2016-17$ \\
\hline $\begin{array}{l}\text { \% Yoy } \\
\text { increase }\end{array}$ & NA & 3.315473 & 6.443258 & 4.568662 & 10.76823 & 2.273685 \\
\begin{tabular}{l} 
Increase from 12-17 \\
\hline $\begin{array}{l}\text { Inflation- } \\
\text { adjusted } \\
\text { gains }\end{array}$ \\
\end{tabular} & & & & & $30 \%$ \\
\hline & NA & $-6.12 \%$ & $-4.59 \%$ & $-5.37 \%$ & $0.03 \%$ & $0.33 \%$ \\
\hline
\end{tabular}

${ }^{\wedge} \mathrm{All}$ costs are in INR

\section{Cost of Hospitalization for Fortis Healthcare Limited}

\begin{tabular}{lllllll}
\hline & $2011-12$ & $2012-13$ & $2013-14$ & $2014-15$ & $2015-16$ & $2016-17$ \\
\hline ALOS $^{3}$ & 4 & 3.83 & 3.81 & 3.64 & 3.56 & 3.56
\end{tabular}

ARPOB $^{3} 93000001040000011200000126000001370000014500000$

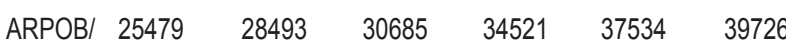

day

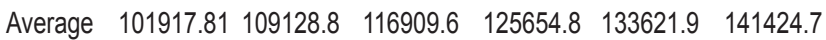

cost of

hospita-

lization

per in-

patient

\begin{tabular}{llllllll}
$\begin{array}{l}\text { Yoy } \\
\text { increase } \\
\text { in costs }\end{array}$ & NA & 0.070753 & 0.071299 & 0.074803 & 0.063405 & 0.058394 \\
$\begin{array}{l}\text { \% Yoy } \\
\text { increase }\end{array}$ & NA & & 7.075269 & 7.129946 & 7.480315 & 6.340485 & 5.839416 \\
\hline
\end{tabular}

Cont...

\begin{tabular}{|c|c|c|c|c|c|c|}
\hline & 2011-12 & 2012-13 & 2013-14 & 2014-15 & $2015-16$ & 2016-17 \\
\hline $\begin{array}{l}\text { Increase } \\
\text { from } \\
2012-17\end{array}$ & & & & & & $39 \%$ \\
\hline \multirow[t]{2}{*}{$\begin{array}{l}\text { Inflation- } \\
\text { adjusted } \\
\text { gains }{ }^{2}\end{array}$} & 101918 & 112166 & 117470 & 123848 & 129786 & 132331 \\
\hline & NA & $-2.71 \%$ & $-0.48 \%$ & $1.46 \%$ & $2.96 \%$ & $6.87 \%$ \\
\hline
\end{tabular}

^All costs are in INR

\section{SUMMARY}

It is evident from the above that the average 'year on year' increase in the 'cost of hospitalization' for Apollo Hospitals is around $6 \%$ and for Fortis Hospitals, it is around $7 \%$ for the last five years considered. The exact increase can be noted from the data above.

And considering the average inflation for these years of $5.39 \%$ (based on $\mathrm{CPI}_{2}$ ), the increase in the cost of hospitalization over these years does not seem to be much more than the average cost of inflation.

I expected the increase in 'cost of hospitalization' to be much more when I started the analysis and the results were somewhat surprising. It would be interesting to see why this is so if more data can be accessed from these hospitals to understand the same.

\section{REFERENCES}

1. Annual Reports of Fortis Healthcare limited from 2012-2017.

2. CPI based inflation rates for the country for all the years 2012.

3. Annual Reports of Apollo Hospital Enterprise limited 2012 -2017 . 